\title{
A First Attempt Towards Reliability- based Calibration of Brazilian Structural Design Codes
}

University of São Paulo - USP

Structural Engineering Department

13566-590 São Carlos, SP, Brazil

\author{
Antônio C. de Souza Jr. \\ antoniocsj@yahoo.com.br \\ University of São Paulo - USP \\ Structural Engineering Department \\ 13566-590 São Carlos, SP, Brazil
}

This paper addresses the reliability-based calibration of partial safety factors for Brazilian design codes NBR8681:2003 (Actions and Safety of Structures) and NBR8800:2008 (Design of Steel and Steel-Concrete Composite Structures). To the author's knowledge, these codes have never been subject to reliability-based calibration of partial and load combination factors. This paper represents a first effort in reaching this goal. The present calibration effort is based on actual data for wind loads in south east of Brazil, but uses mainly international data for other problem parameters. So far, the investigation is limited to structural steel members. The investigation leads to a set of optimized partial safety factors, which are compared to partial factors currently used in Brazilian design codes. Results show that the optimized set of partial factors leads to more uniform reliability for different design situations and load combinations. The investigation includes an analysis of the economical impact of replacing the current set of partial factors by the calibrated factors found in this paper. It is shown that, with an optimized set of partial safety factors, it is possible to maintain the current level of reliability and still produce a $5 \%$ average reduction in expenditure with structural materials, nationwide. The paper also points to general similarities between Brazilian design codes, the new generation of EUROCODES and American ANSI/AISC codes. These codes are compared in terms of their ability to produce uniform reliability for different design situations.

Keywords: structural reliability, design codes, code calibration

\section{Introduction}

In the late 70's and early 80's, ANSI/AISC structural design codes have undergone significant improvements, with a migration from allowable stress to limit state (partial factor) design. This migration process was guided by reliability-based calibration of the partial safety factors of the new codes. The calibration was conducted ensuring that the safety level of the new codes reflected the general safety level of old codes, which was regarded as result of collective knowledge and experience-based optimization over the years. This process was well documented in the literature (Ellingwood et al., 1980; Ellingwood and Galambos, 1982).

More recently, European design codes also migrated to a limit state partial factor format. European Union member states are now individually defining the partial safety factors to be used within each country. Individual efforts in performing the reliability based calibration of these partial factors have been reported (Gayton et al., 2004; Gulvanessian and Holicky, 2005).

The Brazilian "Actions and Safety of Structures: Procedures" (NBR8681:2003) and "Design of Steel and Steel-concrete Composite Buildings" (NBR8800:2008) were also recently converted to a limit state partial factor format. Both codes are largely based on the EUROCODES, but their conception was not accompanied by a consistent (e.g., reliability-based) tropicalization of partial safety factors. Adaptations of partial safety factors were based on subjective judgment, derived from the experience of committee members. The same partial and load combination factors are currently being revised in application to the EUROCODES.

The present paper is a first effort towards verifying the adequacy of partial factors currently used in Brazilian design codes. Statistical description of resistance and load parameters for the Brazilian reality is currently incomplete. There have been no comprehensive studies of uncertainties in dead and life loads reported in the literature. For these parameters, international data is used in the present investigation. Some information on material resistance for steel, concrete and wood is available, but in scattered form. This

Paper accepted December, 2009. Technical Editor: Nestor A. Zouain Pereira information still has to be collected and compiled for future calibration work. Statistics for the occurrence of winds in Brazil have been reported (Santos, 1989; Riera and Rocha, 1998) and are used in the present study.

The article is laid out as follows. Section 1 introduces the subject and locates it in a historical and geographical perspective. Section 2 presents the basic formulations of codified limit state design, with particular attention to similarities between the ANSI/AISC, EUROCODE and Brazilian code formats. Section 3 presents de statistical data used in the present calibration effort. In section 4, the calibration (optimization) problem is formulated. Results of a first calibration are presented in Section 5. Section 6 presents a comparison of different code formats (ANSI/AISC versus EUROCODE) in terms of calibration of partial factors. Section 7 presents a study of the potential economical impact of implementing the partial safety factors found in the present calibration effort. Section 8 closes the paper with some conclusions.

\section{Nomenclature}

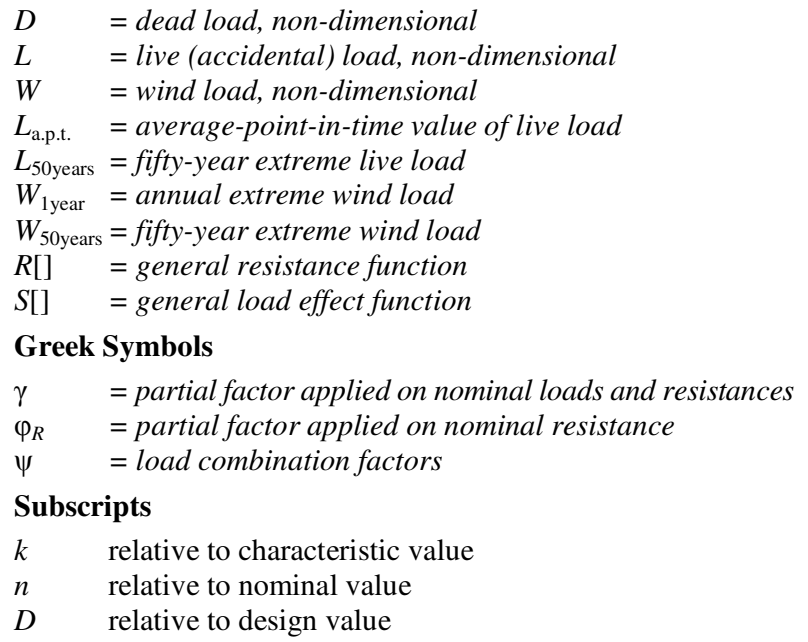




\section{Codified Limit State Design}

\section{ANSI/AISC Load and Resistance Factor Design}

The design format used in current ANSI/AISC design codes came to be known as Load and Resistance Factor Design (LRFD). The general design equation is given by (ASCE, 2006):

$$
\gamma_{D} \cdot D_{n}+\gamma_{i} \cdot Q_{n i}+\gamma_{j} \cdot Q_{n j} \leq \varphi_{R} \cdot R_{n}
$$

where index ${ }_{n}$ stands for nominal value, $\gamma$ are partial factors applied on (nominal values of) loads, $D_{n}$ is the (nominal value of) dead load (self-weight), $Q_{n i}$ is the principal variable load, $Q_{n j}$ is the accompanying variable load, $R_{n}$ is a nominal member resistance and $\varphi_{R}$ is a partial safety factor applied on nominal member resistance.

Reliability-based calibration of partial factors of ANSI/AISC codes has been facilitated by the simplicity of these in comparison to European and Brazilian codes. This simplicity arises from use of a single resistance factor for member resistance, but also from using a set of pre-defined load combination equations. A different set of partial safety factors is used for each load combination, and the combined factored load effects are given by:

$$
S_{D}=\max \left[\begin{array}{l}
1.4 D_{n} \\
1.2 D_{n}+1.6 L_{n} \\
1.2 D_{n}+1.6 S_{n}+\left(0.5 L_{n} \text { or } 0.8 W_{n}\right) \\
1.2 D_{n}+1.3 W_{n}+0.5 L_{n} \\
1.2 D_{n}+1.5 E_{n}+\left(0.5 L_{n} \text { or } 0.2 S_{n}\right) \\
0.9 D_{n}-\left(1.3 W_{n} \text { or } 1.5 E_{n}\right)
\end{array}\right]
$$

where $S_{D}$ is the design load, $L$ is the live load (called accidental load in Brazilian codes), $W$ is the wind load, $S$ is the snow load and $E$ is the earthquake load.

Determination of load factors for ANSI/AISC codes was also simplified by the rule used in load combinations. These codes are based on Turkstra's load combination rule (Turkstra and Madsen, 1980), where the extreme of one variable load (called principal load in the combination) is combined with the average-point-in-time value of the accompanying loads. This simplifies the reliability problem, which becomes time-invariant, with random load processes replaced by (extreme-value) random variables.

\section{NBR8800 and EUROCODE Formats}

The general format adopted in Brazilian NBR8800:2008 and in European design codes uses a single load combination expression:

$$
S\left[\gamma_{D} \cdot D_{n}+\gamma_{i} \cdot Q_{n i}+\sum_{j \neq i}^{n} \psi_{j} \cdot \gamma_{j} \cdot Q_{n j}\right] \leq R\left[\frac{r_{k}}{\gamma_{R}}\right]
$$

where $S[$.$] is a load effect function, R[$.$] is a resistance function, r_{k}$ is a characteristic material resistance, $\gamma_{R}$ is the resistance factor (one for each structural material), $\gamma_{i}$ are partial load factors, $\psi_{j}$ are load combination factors and other symbols are equivalent to Eq. (1). Here, one resistance factor is used for each structural material involved. The format is more flexible in terms of resistance modeling, but less flexible is terms of load combinations, as will be shown in Section 6: Calibration in Other Code Formats.

In this study, load combinations involving permanent and variable actions are considered. Accidental (live) and wind variable actions are considered in the study, leading to five load combination equations, following Eq. (3):

$$
S_{D}=\max \left[\begin{array}{l}
\gamma_{D} D_{n} \\
\gamma_{D} D_{n}+\gamma_{L} L_{n} \\
\gamma_{D} D_{n}+\gamma_{W} W_{n} \\
\gamma_{D} D_{n}+\gamma_{L} L_{n}+\gamma_{W} \psi_{W} W_{n} \\
\gamma_{D} D_{n}+\gamma_{W} W_{n}+\gamma_{L} \psi_{L} L_{n}
\end{array}\right]
$$

The first three combinations are particular cases of the last two, when variable loads $L_{n}$ and/or $W_{n}$ are zero or non-existent. The first three equations are reproduced here for completeness, to stress the fact that load combinations involving only some of the variable loads are also relevant in calibration of Brazilian design codes.

\section{Dead and Live Loads}

Actual data on dead and live load uncertainty is not available for the Brazilian reality. In this investigation, it is assumed that no significant differences exist in dead and life loads between Brazil and what is reported in international references. This assumption should be investigated in the future.

Dead and live load statistics used in this paper are based on data reported by Ellingwood et al. (1980), as presented in Table 1 .

\section{NBR8681 Code Format}

The general design format adopted in Brazilian code NBR8681:2003 differs slightly from the format adopted in NBR8800:

$$
S\left[\gamma_{D} \cdot D_{n}+\gamma_{i} \cdot\left(Q_{n i}+\sum_{j \neq i}^{n} \psi_{j} \cdot Q_{n j}\right)\right] \leq R\left[\frac{r_{k}}{\gamma_{R}}\right]
$$

The symbols are similar to those used in Eq. (3). In this format, the partial factor for the principal variable action is multiplied by the combination value of the secondary variable action. In the author's understanding, and from a theoretical point of view, there is no justification for this format; hence the NBR8800 format should be preferred. Reliability indexes obtained for current and for calibrated factors, for these two formats, are compared in Section 6.

The load combination equations corresponding to Eq. (4) are:

$$
S_{D}=\max \left[\begin{array}{l}
\gamma_{D} D_{n} \\
\gamma_{D} D_{n}+\gamma_{L} L_{n} \\
\gamma_{D} D_{n}+\gamma_{W} W_{n} \\
\gamma_{D} D_{n}+\gamma_{L}\left(L_{n}+\psi_{W} W_{n}\right) \\
\gamma_{D} D_{n}+\gamma_{W}\left(W_{n}+\psi_{L} L_{n}\right)
\end{array}\right]
$$

\section{Comparison of Code Formats}

The symbols used in this paper to describe the different code formats differ somewhat from the symbolism used in each of the described codes. This was done on purpose, since our objective is to stress the similarities between the code formats, and later compare these formats (see Section 6).

One of the main differences between the ANSI/AISC and Brazilian (or European) code formats is the way the partial resistance factor is applied. In ANSI/AISC codes, a single partial resistance factor is applied to nominal member resistance. In 
Brazilian and European design codes, a different partial resistance factor is used for each structural material. It is widely accepted (Kogut and Chou, 2004; Mohamed et al., 2001) that the ANSI/AISC format lacks flexibility, and results in non-uniform reliability in problems involving more than one structural material (for example, reinforced concrete or steel-concrete composites).

Use of a single resistance factor in ANSI/AISC codes makes the reliability-based calibration easier. In calibration of EUROCODES, fixed sensitivity factors have been used to split the load and resistance parts of the problem (Holicky, 2008), so that calibration can be performed separately.

Differences between different code formats, with respect to resistance modeling, are not explored herein, but will be addressed in future studies. The present study is limited to structural steel members. Moreover, in the present study, a linear resistance model $R[$.$] is assumed, hence the partial resistance factors in the$ ANSI/AISC and Brazilian formats become equivalent:

$$
\frac{1}{\gamma_{R}}=\varphi_{R}
$$

The present study explores differences related to load combinations in distinct code formats. In this regard, it is noted that the ANSI/AISC code format is more flexible than the European or Brazilian counterparts, since it uses one set of partial factors for each load combination equation, whereas Brazilian codes use one single set of partial (and combination) factors for all load combination expressions.

The general format of the ANSI/AISC code, for load combinations involving live and wind loads, would lead to the following design equations:

$$
S_{D}=\max \left[\begin{array}{l}
\gamma_{1} D_{n} \\
\gamma_{2} D_{n}+\gamma_{6} L_{n} \\
\gamma_{3} D_{n}+\gamma_{7} W_{n} \\
\gamma_{4} D_{n}+\gamma_{8} L_{n}+\gamma_{10} W_{n} \\
\gamma_{5} D_{n}+\gamma_{9} W_{n}+\gamma_{11} L_{n}
\end{array}\right]
$$

These are not the design equations of the ASCE:2006 code, Eq. (2). Equation (8) is the ANSI/AISC equivalent to Eqs. (4) and (6). It is noted that this format, which uses different load factors in each load combination, has 11 degrees of freedom, whereas combinations (4) and (6) have 5 degrees of freedom each. This difference between design code formats is explored in Section 6 .

\section{Statistics of Load and Resistance Parameters}

\section{Structural Steel Members}

Statistics on structural steel member resistance is taken from Ellingwood et al. (1980). Statistics for different steel members (tension members, compact beams, concentrically loaded columns and beam columns) do not vary too much. Hence, as approximation, a single set of structural steel statistics is used in the present calibration effort: mean of $1.18 R_{n}$, coefficient of variation (c.o.v.) of 0.15 . This c.o.v. accounts for material uncertainty and model error. The mean of $1.18 R_{n}$ is already adjusted to take into account the rate of loading, for combinations involving wind. These values are in agreement with results reported by Pimenta et al. (2008) regarding bending of steel beams in Brazil.

Table 1 summarizes statistics of load and resistance variables considered in this study. In Table $1, L_{50 \text { years }}$ and $W_{50 \text { years }}$ are the 50 year extreme live and wind loads, respectively, which are generally combined with the annual extreme wind $\left(W_{\text {lyear }}\right)$ and with the average-point-in-time live load $\left(L_{\text {a.p.t }}\right)$, following Eq. (13).

Table 1. Statistics of resistance and load variables.

\begin{tabular}{|l|l|c|c|c|}
\hline Variable & mean & c.o.v. & distribution \\
\hline \multicolumn{2}{|l|}{ Res. of steel members } & $1.18 R_{n}$ & 0.15 & lognormal \\
\hline \multicolumn{2}{|l|}{ Dead load } & $1.05 D_{n}$ & 0.10 & normal \\
\hline \multirow{3}{*}{ Life load: } & $L_{\text {a.p.t. }}$ & $0.25 L_{n}$ & 0.55 & Gamma \\
\cline { 2 - 5 } & $L_{50 \text { years }}$ & $1.00 L_{n}$ & 0.25 & Gumbel \\
\hline \multirow{3}{*}{ Wind load } & $W_{\text {lyear }}$ & $0.33 W_{n}$ & 0.47 & Gumbel \\
\cline { 2 - 5 } & $W_{50 \text { years }}$ & $0.90 W_{n}$ & 0.34 & Gumbel \\
\hline
\end{tabular}

\section{Wind Loads in Central-South of Brazil}

Statistics of annual extreme storm winds for the central-south of Brazil have been reported by Santos (1989) and Riera and Rocha (1998). Wind speed series of 15 to 29 years, recorded on 11 meteorological stations, were used by Santos (1989) to divide the central-south of Brazil in 5 meteorological provinces. The author constructed regression curves, which allow one to evaluate mean and standard deviation of maximum annual wind speeds at any location within the 5 provinces, according to type of storm and wind direction. Maximum annual wind speeds, independent of storm type and direction, can also be evaluated.

The present study is based on evaluation of the model of Santos at 16 locations (11 meteorological stations and geometrical centers of 5 provinces). Mean and standard deviation of maximum annual wind speeds were evaluated at these locations and fitted to Gumbel distributions. These were then converted to 50 year extremes using:

$$
F_{W_{\text {Soyyars }}}(x)=\left(F_{W_{1 \text { year }}}(x)\right)^{50}
$$

By comparing the mean of extreme wind speeds at the 16 locations with nominal (design) wind speeds (NBR6123:1988), the wind statistics shown in Table 2 were obtained.

\section{Table 2. Statistics of wind speeds.}

\begin{tabular}{|l|l|l|l|l|}
\hline \multicolumn{2}{|l|}{ Variable } & mean* & c.o.v. & distribution \\
\hline \multirow{2}{*}{$\begin{array}{l}\text { Wind } \\
\text { speed: }\end{array}$} & $V_{\text {lyear }}$ & $0.57 V_{n}$ & 0.21 & Gumbel \\
\cline { 2 - 5 } & $V_{50 \text { years }}$ & $0.95 V_{n}$ & 0.13 & Gumbel \\
\hline
\end{tabular}

$*_{\text {where }} V_{n}$ is the nominal (design) wind speed, following NBR6123:1988.

Wind speed statistics were converted into wind pressure, using:

$$
W=\frac{1}{2} \rho \cdot c \cdot V^{2}
$$

where $\rho$ is air density and $c$ is an aerodynamic coefficient, accounting for shape, gust (turbulence) and exposition. The quadratic relation between wind speeds and wind pressures applies to bias factors. Bias factors for wind pressure, presented in Table 1, were obtained from:

$$
\frac{\mu_{W}}{W_{n}}=\left(\frac{\mu_{V}}{V_{n}}\right)^{2}
$$

Due to the quadratic relationship, the coefficient of variation of wind pressure $\left(V_{W}\right)$ is obtained as $V_{W} \approx 2 \cdot V_{V}$, for a deterministic coefficient $c$. The uncertainty of shape $\left(V_{a}\right)$, gust $\left(V_{g}\right)$ and exposition $\left(V_{r}\right)$ factors is taken into account by means of a second moment mean value approximation (JCSS, 2001): 


$$
V_{W}^{2}=V_{a}^{2}+V_{g}^{2}+V_{r}^{2}+\left(2 \cdot V_{V}\right)^{2}
$$

This leads to the wind pressure statistics reported in Table 1 (Souza Jr., 2009). As pointed out by Riera and Rocha (1998), modeling both wind speeds and pressures by Gumbel distributions is formally inconsistent. However, Ellingwood et al. (1980) found that incorporation of uncertainties in aerodynamic coefficients leads to best fit of wind pressure data by Gumbel distributions.

\section{Reliability-Based Code Calibration}

Reliability-based code calibration is the determination of the partial safety factors in Eqs. (1), (3) or (5), in order for the range of structural designs resulting from these equations to present minimal variations with respect to a pre-selected target reliability level $\left(\beta_{T}\right)$.

Different design situations, covered by the code being calibrated, have to be considered. This includes structural elements under tensile, compressive or bending loading, instability of columns, and so on. This also includes designs resulting in distinct ratios between the different loads being combined. Hence, it is customary in load calibration work to consider different ratios between live and dead loads $\left(L_{n} / D_{n}\right)$ and between wind and dead loads $\left(W_{n} / D_{n}\right)$.

The calibration of partial factors to be used in a given design code is accomplished by solving an unconstrained optimization problem:

$$
\text { minimize: } \Psi=\sum_{i=1}^{n} \sum_{j=1}^{m}\left(\beta_{T}-\min _{k}\left[\beta_{i j k}\right]\right)^{2} \cdot w_{i j}
$$

where $n$ and $m$ are the number of load ratios (design situations) considered, $\beta_{T}$ is the target reliability index, $\beta_{i j k}$ is the reliability index for design $i j$ and for the $k^{\text {th }}$ load combination. Expression (12) does not penalize reliability indexes that are below the target, as proposed by Sorensen et al. (1994).

For each load ratio considered, a different weight is used in the combination ( $w_{i j}$ in Eq. (12)), according to the relative significance of that load ratio in actual code use. Load ratios and weights used in this paper are shown in Table 3. These values were adapted from Ellingwood et al. (1980).

Table 3. Weights of the different load ratios considered in the calibration.

\begin{tabular}{|l|c|ccccccc|}
\hline \multirow{3}{*}{$w_{i j}$} & \multicolumn{7}{|c|}{$W_{n} / D_{n}$} \\
\hline \multirow{6}{*}{$L_{n} / D_{n}$} & & 0.0 & 0.5 & 1.0 & 1.5 & 2.0 & 3.0 & 5.0 \\
\cline { 2 - 9 } & 0.0 & 40 & 10 & 20 & 25 & 35 & 7 & 3 \\
& 0.5 & 10 & 20 & 30 & 35 & 45 & 17 & 13 \\
& 1.0 & 20 & 30 & 40 & 45 & 55 & 27 & 23 \\
& 1.5 & 25 & 35 & 45 & 50 & 60 & 32 & 28 \\
& 2.0 & 35 & 45 & 55 & 60 & 70 & 42 & 38 \\
& 3.0 & 7 & 17 & 27 & 32 & 42 & 14 & 10 \\
& 5.0 & 3 & 13 & 23 & 28 & 38 & 10 & 6 \\
\hline
\end{tabular}

The reliability problem corresponding to each design situation is constructed from the nominal loads. For example: considering a unitary (non-dimensional) nominal dead load $D_{n}=1$, load ratios $W_{n} / D_{n}=1$ and $L_{n} / D_{n}=1$, using Eq. (4) (load combinations for NBR8800) and partial factors recommended in this code (reproduced in Table 3), one obtains the design load as 3.8 units. Using the resistance factor, the nominal resistance is obtained as $R_{n}=1.1 \cdot 3.8=4.18$. From the nominal values of loads and resistances, and using the data presented in Table 1, statistics of the random variable loads and resistances are "re-constructed". These are used in the reliability analyses.
Two linear limit state functions are used in the reliability analyses:

$$
\begin{aligned}
& g_{1}(\mathbf{X})=R-\left(D+L_{50 \text { years }}+W_{1 \text { year }}\right)=0 \\
& g_{2}(\mathbf{X})=R-\left(D+L_{\text {a.p.t. }}+W_{50 \text { years }}\right)=0
\end{aligned}
$$

where $\mathbf{X}$ is a vector of random variables.

These two equations account for the five load combination cases, Eqs. (4) and (6), since some load ratios are zero (following Table 3). It is interesting to note the equivalence between limit state functions used in reliability analyses (Eq. (13)) and the corresponding code design equations (Eqs. (1), (3) and (5)). This equivalence explains why modern codes are said to be based on "limit state design".

The limit state functions, Eq. (13), define boundaries which divide the failure and survival domains:

$$
\begin{array}{ll}
\Omega_{f}=\{\mathbf{x} \mid g(\mathbf{x}) \leq 0\} & \text { is the failure domain } \\
\Omega_{s}=\{\mathbf{x} \mid g(\mathbf{x})>0\} & \text { is the safety domain }
\end{array}
$$

For each limit state, the failure probability is evaluated as:

$$
P_{f}=P[g(\mathbf{x}) \leq 0]=\int_{\Omega_{f}} f_{\mathbf{X}}(\mathbf{x}) d \mathbf{x}
$$

Equation (15) is solved via de First Order Reliability Method (FORM), using the StRAnD (Structural Reliability Analysis and Design) program (Beck, 2008). This solution involves a transformation of the random variables to the standard normal space, and a search for the most probable failure point, or design point. The reliability index $\beta$ is the (minimal) distance between the design point and the origin of the standard normal space. The reliability index is related to the failure probability by the expression:

$$
P_{f}=\Phi[-\beta]
$$

For the two limit states considered herein (Eq. (13)), and following Turkstra's rule, the reliability index for design situation $i j$ is given by the smallest value between the two load combinations:

$$
\beta_{i j}=\min \left[\beta_{i j 1}, \beta_{i j 2}\right]
$$

The optimization problem (Eq. (12)) is solved using a particle swarm optimization (PSO) algorithm, implemented in the StRAnD program.

\section{Calibration Results for NBR8800 and $\beta_{T}=\mathbf{3 . 0}$}

\section{Partial Factors to Obtain $\boldsymbol{\beta}_{T}=3.0$ Exactly}

Recent studies by the authors (Beck and Dória, 2008; Oliveira et al., 2008; Beck et al., 2009) reveal that the reliability index of structures designed according to Brazilian code NBR8800:2008 lie in the range from $\beta=2.3$ to $\beta=4.5$. Therefore, in this study, the target reliability index was first selected as $\beta_{T}=3.0$.

A preliminary analysis was made to find the partial safety factors that would lead to the target reliability index exactly, in the NBR8800 code format (Eq. (4)). Results of this analysis are shown in Figs. 1 and 2. Partial factors shown in these figures serve as a guide to the fixed set of partial factors to be found in the calibration 
process. The figures show nearly constant partial factors for resistance and dead loads $\left(\gamma_{R}=1.1, \gamma_{D}=1.1\right)$, and some variation on the ideal partial safety factors for the variable actions.



Figure 1. Partial safety factors to obtain $\beta_{T}=3.0$ exactly in $D+L+W$ load combination, $L$ main load.



Figure 2. Partial safety factors to obtain $\beta_{T}=3.0$ exactly in $D+L+W$ load combination, $W$ main load.

\section{Calibration Results for NBR8800}

Reliability-based calibration of the partial factors used in design code NBR8800 amounts for finding the set of five partial and combination factors in Eq. (4), plus the resistance factor $\gamma_{R}$, in order to produce the smallest variations of reliability indexes with respect to the target reliability.

The problem is not easy to solve when the six factors are sought simultaneously. Some convergence problems were encountered since the "optimum" dead load factor $\gamma_{D}$, for combinations involving only dead load $\left(L_{n} / D_{n}=W_{n} / D_{n}=0\right)$, is quite different from the "optimum" $\gamma_{D}$ for combinations involving variable actions. Hence, the author's experience in preliminary calibration runs was used to fix the values $\gamma_{R}=1.10$ and $\gamma_{D}=1.35$. The optimization process was then run again to find the remaining partial factors. Results are presented in Table 4. In Table 4, the partial factors found in the present calibration effort are compared with the factors currently used in Brazilian design code NBR8800:2008.
Table 4. Partial safety factors for Brazilian codes and calibrated in this paper.

\begin{tabular}{|c|c|c|c|}
\hline $\begin{array}{l}\text { Partial or } \\
\text { comb. factor }\end{array}$ & $\begin{array}{c}\text { NBR8800 } \\
\text { NBR8681 }\end{array}$ & $\begin{array}{c}\text { Calibration } \\
\text { for } \beta_{T}=3.0\end{array}$ & $\begin{array}{c}\text { Calibration } \\
\text { for } \beta_{T}=2.8\end{array}$ \\
\hline$\gamma_{R}$ & 1.10 & 1.10 & 1.10 \\
\hline$\gamma_{D}$ & 1.35 & 1.35 & 1.30 \\
\hline$\gamma_{L}$ & 1.50 & 1.65 & 1.50 \\
\hline$\gamma_{W}$ & 1.40 & 1.70 & 1.60 \\
\hline$\psi_{L}$ & 0.70 & 0.30 & 0.30 \\
\hline$\psi_{W}$ & 0.60 & 0.30 & 0.35 \\
\hline$\gamma_{L} \cdot \psi_{L}$ & 1.05 & 0.50 & 0.45 \\
\hline$\gamma_{W} \cdot \psi_{W}$ & 0.84 & 0.51 & 0.56 \\
\hline
\end{tabular}

Table 4 shows significant differences between the partial factors currently in use and the factors found through the calibration process. It is observed that the calibrated factors are larger for the principal loads $\left(\gamma_{L}\right.$ and $\left.\gamma_{W}\right)$, but the combination factors are significantly smaller, resulting in significantly smaller values of the accompanying variable action (product $\gamma \cdot \psi$ ).

Reliability indexes resulting from use of these partial factors are compared graphically in Figs. 3 and 4. Figure 3 shows reliability indexes obtained for all designs (load ratios) considered, with $\beta$ given as the minimum between the two (formally, five) limit state (or load combination) equations. The design load is the largest amongst the combinations considered (following Eq. (4)), and the reliability index is the smallest between the two limit state equations (Eq. (13)).

In Figure 3, reliability index results are shown for all design situations. Figure 4 shows only the lower and upper bounds of these indexes, in terms of load ratios $W_{n} / D_{n}$ (left) and $L_{n} / D_{n}$ (right). The bounds show the uniformness of (or lack of) reliability indexes obtained using the different sets of partial safety factors.

In Figures 3 and 4, it can be clearly seen that the calibrated set of partial and combination factors leads to more uniform reliability indexes. Moreover, the average reliability index obtained with the calibrated set is larger than the average reliability obtained with the current set of factors.

The set of calibrated partial factors is an optimum (or, at least, a better) set, in comparison to what is currently used in Brazilian design codes. Of course, this observation must be subject to further confirmation, given the limitations of the present calibration effort.

Since there is no evidence of previous calibration or of proper tropicalization of partial safety factors used in Brazilian design codes, the results obtained in this paper are very significant, and should be regarded as a stimulus for further investigation.

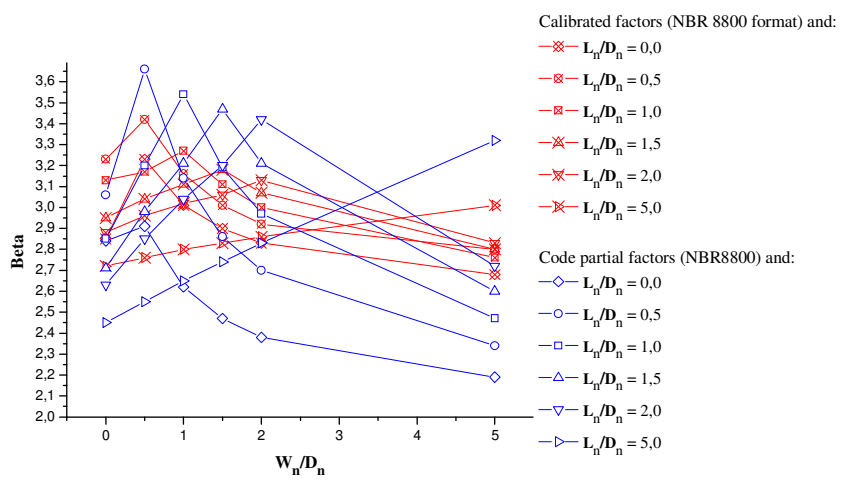

Figure 3. Reliability indexes for Brazilian NBR8800 code and for calibrated partial factors $\left(\beta_{T}=3.0\right)$. 



Figure 4. Reliability index bounds for Brazilian NBR8800 code and for calibrated partial factors $\left(\beta_{T}=3.0\right)$.

\section{Calibration in Other Code Formats}

In this section, the calibration procedure is used to find the optimum set of partial factors in the NBR8681 and ANSI/AISC code formats.

Calibration in the NBR8681 format (Eq. (6)) actually resulted in the same set of partial factors presented in Table 4 (second column for $\beta_{T}=3.0$ ). Clearly, this is due to the fact that partial factors $\gamma_{L}$ and $\gamma_{W}$ found in the calibration for NBR8800 are very similar. Figure 5 shows that both formats, using the calibrated factors, lead to virtually the same range of variation of reliability indexes. In Figure 6, the two design formats are compared when using the set of partial factors currently in use in the Brazilian codes. The differences between the two formats are more noticeable in this case, although still acceptably small.

It turns out that, in practice, the two design formats (NBR8800 and NBR8681) are equivalent. The authors, however, still consider that the format of NBR8800 is more logical, since it maintains the theoretical independency between the partial factors for principal and accompanying variable actions.

For the purpose of illustration, the calibration was also done in the ANSI/AISC code format, that is: using a different set of partial factors for each load combination equation (Eq. (8)). The resulting calibrated partial factors are $\gamma_{R}=1.10\left(\right.$ or $\left.\varphi_{R}=0.91\right)$ and


Figure 5. Reliability index bounds for calibrated partial factors $\left(\beta_{T}=3.0\right.$ ), NBR8800 and NBR8681 code formats.

$$
S_{D}=\max \left[\begin{array}{l}
1.40 D_{n} \\
1.10 D_{n}+1.85 L_{n} \\
1.10 D_{n}+1.95 W_{n} \\
1.10 D_{n}+1.70 L_{n}+0.60 W_{n} \\
1.05 D_{n}+0.50 L_{n}+1.80 W_{n}
\end{array}\right]
$$

These load combinations are equivalent to those used in calibration of Brazilian codes, but they can be grossly compared with the partial factors currently in use in ANSI/AISC codes, Eq. (2). In their calibration effort, Ellingwood et al. (1980) also found the "optimum" partial factor for dead loads to be equal to 1.10 , as in the present study. They, however, preferred to set the dead load factor to 1.2, following Eq. (2).

The range of reliability indexes obtained using the partial factors calibrated in the NBR8800 and ANSI/AISC code formats are compared in Fig. 7. It can be seen that the ANSI/AISC format leads to greater uniformity of reliability indexes. This happens because the ANSI/AISC format is more flexible in terms of representing the different load combinations. As argued above, the ANSI/AISC format has 11 degrees of freedom to deal with the same load combinations that, in the Brazilian format, takes 5 partial safety and combination factors. This difference in flexibility leads to the results observed in Fig. 7. 

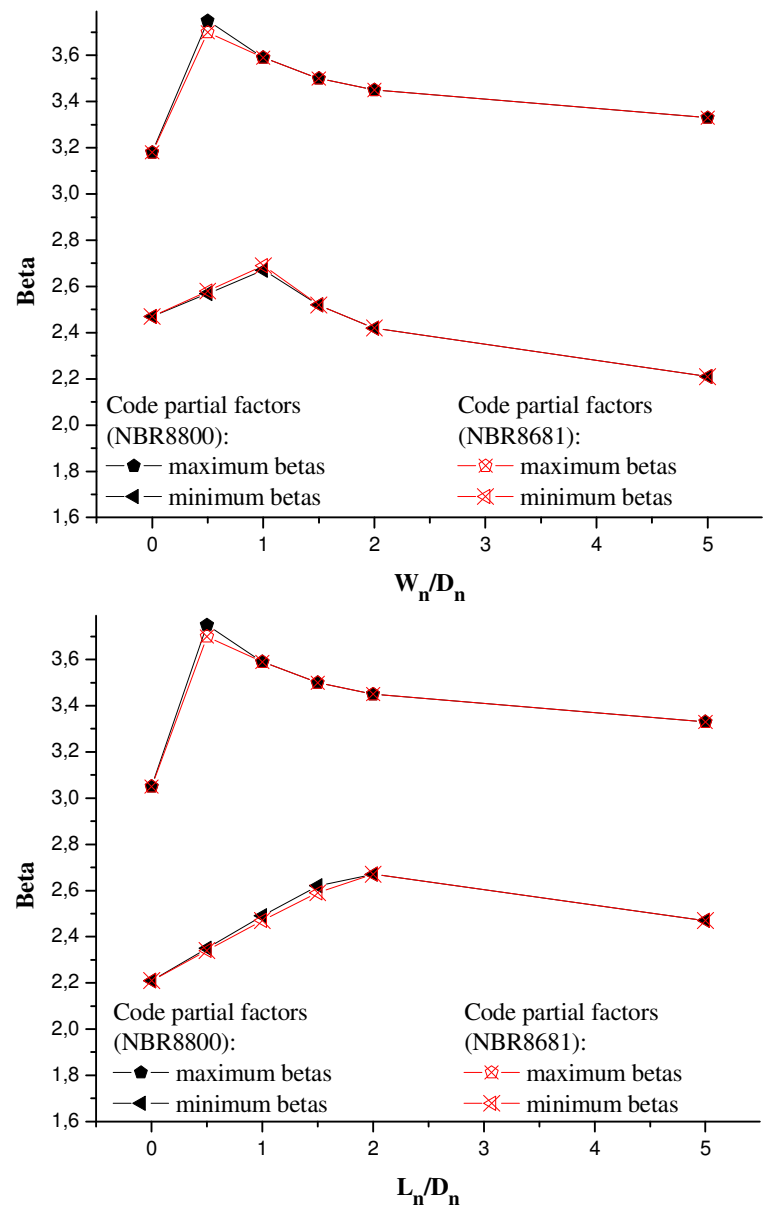

Figure 6. Reliability index bounds for partial factors currently in use in Brazilian codes NBR8800 and NBR8681.

\section{Economical Impact}

In this paper, a set of "optimal" partial safety factors for Brazilian design codes NBR8800 and NBR8681 is obtained. This set is optimum in the sense that it produces more uniform reliability, in comparison to the partial factors currently in use in these codes.

A recommendation of change in the partial safety factors used in these codes must be accompanied by an analysis of the economical impact of such changes. The weights used to describe the relative importance of each design situation (Table 3) can be used for this purpose.

Considering a unitary nominal dead load $\left(D_{n}=1\right)$ as reference, the distinct load ratios shown in Table 3 and the partial factors currently in use in the codes, a weighted sum of design loads is obtained as:

$$
\bar{S}_{D}=\sum_{i=1}^{n} \sum_{j=1}^{m} \frac{w_{i j}}{\sum w_{i j}} \cdot \max \left(\begin{array}{l}
\gamma_{D}+\left.\gamma_{L} \cdot \frac{L_{n}}{D_{n}}\right|_{i}+\left.\gamma_{W} \cdot \psi_{W} \cdot \frac{W_{n}}{D_{n}}\right|_{j} \\
\gamma_{D}+\left.\gamma_{L} \cdot \psi_{L} \cdot \frac{L_{n}}{D_{n}}\right|_{i}+\left.\gamma_{W} \cdot \frac{W_{n}}{D_{n}}\right|_{j}
\end{array}\right)
$$
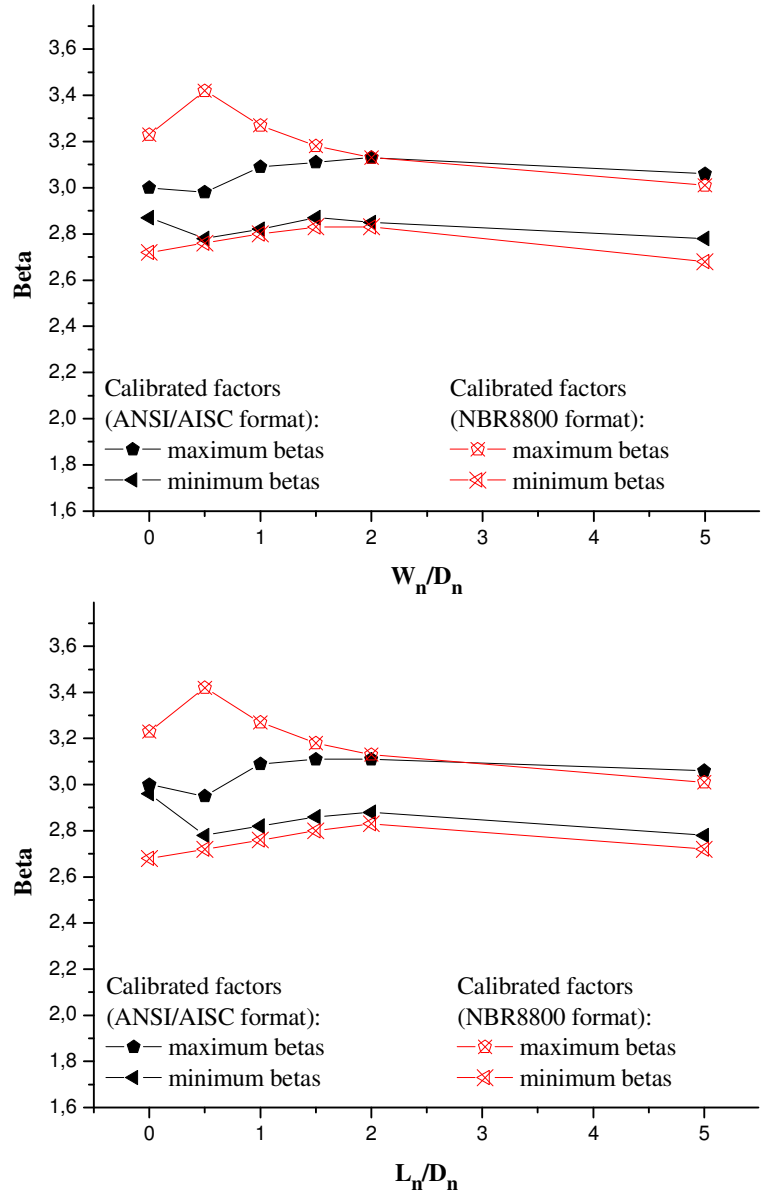

Figure 7. Reliability index bounds for calibrated partial factors $\left(\beta_{T}=3.0\right)$, NBR8800 and ANSI/AISC code formats.

This weighted sum of design loads can then be compared with the same sum obtained with the calibrated partial safety factors. The difference in the weighted sums is a measure of the impact of changing the partial safety factors. The economical impact can be assumed to be proportional to this weighted sum of design loads.

Applying this procedure to the partial safety factors shown in Table 4 (and calibrated for $\beta_{T}=3.0$ ), it is found that the calibrated set produces an increase of $1 \%$ in the weighed sum of design loads, in comparison to the partial factors currently in use (NBR8800:2008). Figure 4 shows that this increment in design loads is associated with an increase in the lower range of reliability indexes. The calibration not only produces more uniform reliability, but also a slight increase in reliability levels.

The calibration procedure was repeated for a target reliability index of $\beta_{T}=2.8$, which is compatible with the lower range of reliability indexes obtained with the current partial factors of NBR8800. The range of reliability indexes obtained with this new set of partial factors is compared with NBR8800 in Fig. 8. The figure shows that the set of partial factors calibrated for $\beta_{T}=2.8$ produces more uniform reliability, which is greater than or equal to what is obtained with the coefficients of NBR8800.

The set of partial safety and combination factors obtained in the calibration with $\beta_{T}=2.8$ is shown in the third column of Table 4 . This new calibrated set maintains current reliability levels, but produces a reduction of the order of $5 \%$ in the weighted sum of design loads. To understand the impact of this result, we must recall that it is assumed to be equivalent to a $5 \%$ reduction in expenditure with structural materials nationwide. 



Figure 8. Reliability index bounds for Brazilian NBR8800 code and for calibrated partial factors $\left(\beta_{T}=2.8\right)$.

\section{Conclusions}

This paper presented an investigation of partial safety factors used in Brazilian design codes NBR8681:2003 and NBR8800:2008. A reliability-based calibration of partial safety and combination factors used in these codes was performed. The calibration effort resulted in an optimized set of partial factors, which was shown to produce more uniform reliability for different design situations, in comparison to the partial factors currently in use in these codes.

The calibration performed for a target reliability index of $\beta_{T}=3.0$ resulted in more uniform reliability, and in a slight increase in mean reliability levels, at a "cost" of a $1 \%$ increase in average design loads. For a target reliability of $\beta_{T}=2.8$, the calibration produced more uniform reliability, which is equal to or greater than the current minimum reliability levels, and with a reduction of nearly $5 \%$ in the weighted sum of design loads. The economical impact of this reduction is quite significant.

In the set of partial and combination factors calibrated for $\beta_{T}=2.8$, the wind load factor $\left(\gamma_{\mathrm{W}}\right)$ is increased from 1.4 to 1.6 , but the combination values of secondary loads are reduced. The combination value for live load as secondary action is reduced from 1.05 to 0.45 , and the combination value for wind is reduced from 0.84 to 0.56 . For this new, optimized balance of partial and combination factors, more uniform reliability is obtained, with a $5 \%$ reduction in average design loads.

The study has also shown that the ANSI/AISC code format, which uses one set of partial factors for each load combination expression, is more flexible than the Brazilian or EUROCODE formats, where a single set of partial and combination factors is used. The larger flexibility of ANSI/AISC codes in representing the different load combinations results in more uniform reliability.

Results obtained in this paper have to be confirmed by further investigation, due to limitations of the present calibration effort. Further investigation is already underway, and includes other structural materials as reinforced concrete, steel-concrete composites, masonry and timber structures. Since partial factors on structural materials are expected to account for different uncertainties in structural materials, the calibrated partial factors for loads obtained in this paper are expected to change only marginally.

\section{Acknowledgements}

The authors would like to express their gratitude to Brazilian agencies $\mathrm{CNPq}$ and CAPES for financial support of this research project.

\section{References}

ANSI/AISC 360:2005, 2005, "Specification for Structural Steel Buildings. American Institute of Steel Construction", Chicago, Illinois. ASCE, 2006, "Minimum Design Loads for Buildings and Other Structures". American Society of Civil Engineering.

Beck, A.T., 2008, "Object-oriented time variant reliability analysis". In: 8th World Congress on Computational Mechanics, Venice, Italy.

Beck, A.T. and Doria, A.S., 2008, "Reliability analysis of I-section steel columns designed according to new Brazilian building codes", J. of the Braz. Soc. of Mech. Sci. and Eng., Vol. 30, No. 2, pp. 152-159.

Beck, A.T., Oliveira, W.L.A., DeNardim, S., ElDebs, A.L.H.C., 2009, "Reliability-based evaluation of design code provisions for circular concretefilled steel columns", Engineering Structures, Vol. 31, p. 2299-2308.

Ellingwood, B. and Galambos, T.V., 1982, "Probability-based criteria for structural design", Structural Safety, Vol. 1, pp. 15-26.

Ellingwood, B., Galambos, T.V., MacGregor, J.G. and Cornell, C.A., 1980, "Development of a Probability Based Load Criterion for American National Standard A58",

EUROCODE 2001, "prEN 1990: Basis of Structural Design" - "Annex C: Basis for Partial Factor Design and Reliability Analysis". European Committee for Standardization, Brussels, Final Draft.

Gayton, N., Mohamed, A., Sorensen, J.D., Pendola, M. and Lemaire, M., 2004, "Calibration methods for reliability-based design codes", Structural Safety, Vol. 26, pp. 91-121.

Gulvanessian, H. and Holicky, M., 2005, "Eurocodes: using reliability analysis to combine action effects", Proceedings of the Institution of Civil Engineers, Structures and Buildings, Thomas Telford.

Holicky, M., 2008, "Reliability-based analysis of codified design allowing for production quality", Proceedings of $4^{\text {th }}$ International ASRANet Colloquium, Athens.

JCSS, 2001, "Probabilistic Model Code", Joint Committee on Structural Safety.

Kogut, G.F., Chou, K.C., 2004, "Partial resistance factor design on steelconcrete beam-columns", Engineering Structures, Vol. 26, pp. 857-866.

NBR8681:2003, 2003, "Actions and Safety of Structures: Procedures". ABNT - Brazilian Association of Technical Codes, Rio de Janeiro (in Portuguese).

NBR6123:1988, 1988, "Wind Loads in Buildings". ABNT - Brazilian Association of Technical Codes, Rio de Janeiro (in Portuguese).

NBR8800:2008, 2008, "Design of Steel and Steel-Concrete Composite Structures: Procedures". ABNT - Brazilian Association of Technical Codes, Rio de Janeiro (in Portuguese).

Mohamed, A., Soares, R., Venturini, W.S., 2001, "Partial safety factors for homogeneous reliability of nonlinear reinforced concrete columns", Structural Safety, Vol. 23, pp. 137-156.

Oliveira, W.L., Beck, A.T., ElDebs, A.L.H.C., 2008, "Safety evaluation of circular concrete-filled steel columns designed according to Brazilian building code NBR 8800:2008", IBRACON Structures and Materials Journal, Vol. 1, pp. 212-236.

Pimenta, R.J., Gonzaga, L.G.M., Queiroz, G. and Diniz, S.M.C., 2008, "Basic requisites for reliability analysis of sinusoidal web beams subject to lateral-torsional buckling", Revista Escola de Minas (to appear). 
Rackwitz, R., 2000, "Optimization - the basis for code-making and reliability verification", Structural Safety, Vol. 22, pp. 27-60.

Riera, J.D. and Rocha, M.M., 1998, "Load definition for wind design and reliability assessments: extreme wind climate". In: Rieira and Davenport (eds.), "Wind effects on Buildings and Structures", Balkema, Rotterdam. Santos, M. dos, 1989, "Regionalization of Extreme Wind Velocities and Temperatures in Center-South of Brazil", M.Sc. Thesis, UFRGS (in Portuguese).

Sorensen, J.D., Kroon, I.B. and Faber, M.H., 1994, "Optimal reliabilitybased code calibration”, Structural Safety, Vol. 15, pp. 197-208.
Souza Jr., A.C. de, 2009, “Application of Reliability in Calibration of Partial Safety Factors for Brazilian Structural Design Codes”, Masters Thesis, Escola de Engenharia de São Carlos, USP (in Portuguese).

Stucchi, F.R. and Santos, S.H.C., 2007, "Reliability based comparison between ACI318-05 and NBR6118". Revista IBRACON de Estruturas, Vol. 3, No.2, pp. 230-239.

Turkstra, C.J. and Madsen, H.O, 1980, "Load combinations incodified structural design", Journal of the Structural Division, ASCE, Vol. 116, No. ST12, pp. 2527-2543.

Vrouwenvelder, A.C.W.M., 2002, "Developments towards full probabilistic design codes”, Structural Safety, Vol. 24, pp. 417-432. 